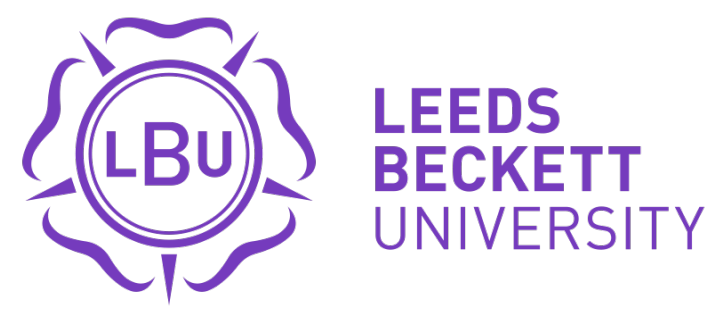

Citation:

Oliffe, JL and Mróz, LW and Bottorff, JL and Braybrook, D and Ward, A and Goldenberg, SL (2015) Heterosexual couples and prostate cancer support groups: a gender relations analysis. Supportive care in cancer : official journal of the Multinational Association of Supportive Care in Cancer, 23 (4). 1127 - 1133. ISSN 0941-4355 DOI: https://doi.org/10.1007/s00520-014-2562-z

Link to Leeds Beckett Repository record:

https://eprints.leedsbeckett.ac.uk/id/eprint/1060/

Document Version:

Article (Accepted Version)

The aim of the Leeds Beckett Repository is to provide open access to our research, as required by funder policies and permitted by publishers and copyright law.

The Leeds Beckett repository holds a wide range of publications, each of which has been checked for copyright and the relevant embargo period has been applied by the Research Services team.

We operate on a standard take-down policy. If you are the author or publisher of an output and you would like it removed from the repository, please contact us and we will investigate on a case-by-case basis.

Each thesis in the repository has been cleared where necessary by the author for third party copyright. If you would like a thesis to be removed from the repository or believe there is an issue with copyright, please contact us on openaccess@leedsbeckett.ac.uk and we will investigate on a case-by-case basis. 


\title{
Heterosexual Couples and Prostate Cancer Support Groups: A Gender Relations
}

\section{Analysis}

John L. Oliffe, Lawrence W. Mróz, Joan L. Bottorff, Debbie E. Braybrook, Amanda Ward and S. Larry Goldenberg

\author{
Affiliations: \\ John L. Oliffe \\ Professor, School of Nursing \\ University of British Columbia, \\ T201-2211 Wesbrook Mall \\ Vancouver, BC, Canada, V6T $2 \mathrm{~B} 3$. \\ Phone: (604) 8227638 \\ Fax: (604) 8227466 \\ Email: john.oliffe@ nursing.ubc.ca \\ Lawrence W. Mróz \\ Post-Doctoral Fellow, Department of Urologic Sciences, Faculty of Medicine \\ University of British Columbia \\ Diamond Health Care Centre \\ 2775 Laurel St., 6th Floor \\ Vancouver, BC, Canada, V5Z 1M9 \\ Email: Larry.Mroz@vch.ca \\ Joan L. Bottorff \\ Professor, School of Nursing \\ University of British Columbia-Okanagan \\ 3333 University Way \\ Kelowna, BC, Canada, V1V 1V7 \\ Email: joan.bottorff@ubc.ca \\ Debbie E. Braybrook \\ PhD Candidate, Centre for Men's Health \\ Institute for Health \& Wellbeing, Faculty of Health \& Social Sciences \\ Leeds Beckett University \\ Room 512 Calverley Building, City Campus \\ Leeds, West Yorkshire, UK, LS1 3HE \\ Email: d.braybrook@leedsbeckett.ac.uk \\ Amanda J. Ward \\ Adjunct Professor, School of Population and Public Health, \\ Faculty of Medicine, University of British Columbia, \\ 2206 East Mall, Vancouver, BC, Canada, V6T 1Z3 \\ Email: Amanda.Ward@fnha.ca
}


S Larry Goldenberg CM, OBC, MD, FRCSC

Professor

Department of Urologic Sciences, Faculty of Medicine

University of British Columbia

Diamond Health Care Centre

2775 Laurel St., 6th Floor

Vancouver BC V5Z 1M9

Email:1.gold@ubc.ca

Key Words: Couples and Prostate Cancer, Heterosexual Gender Relations, Psychosocial Oncology Care 


\begin{abstract}
Men diagnosed with prostate cancer $(\mathrm{PCa})$ can receive supportive care from an array of sources including female partners and prostate cancer support groups (PCSGs). However, little is known about how heterosexual gender relations and supportive care play out among couples who attend PCSGs. Distilling such gender relation patterns is key to understanding and advancing supportive care for men who experience $\mathrm{PCa}$ and their families.
\end{abstract}

Purpose: This study describes connections between heterosexual gender relations and PCa supportive care among couples who attend PCSGs.

Method: In-depth, individual interviews with 30 participants (15 men treated for PCa and their female partners) were analyzed using interpretive descriptive methods. Couples were asked about their relationships, supportive care needs and attendance at PCSGs. A heterosexual gender relations framework was used to theorize the findings.

Results: Findings showed that traditional heterosexual gender relations guided most couples' PCa related support both in and out of PCSGs. Three themes were inductively derived: "Not pushing too hard" - Balancing women's support with men's autonomy; "Confreres" - Men supporting men at PCSGs; and "Women are better at reassuring" Support from and for women.

Conclusions: Couples both aligned to and resisted traditional gender roles to accommodate, explain and rationalize how, as a couple, they approached PCa supportive care needs. 


\section{Introduction}

One in seven Canadian men are diagnosed with prostate cancer (PCa), an illness accompanied by diverse and significant physical and mental health issues [1]. For many men PCa is experienced as a chronic, long-term illness with significant impacts on gender roles, identities and intimate relationships [2]. Psychosocial supports and information are therefore integral to men's illness-management, and within heterosexual couples women often play important roles in the direct provision of care and/or affirmation about the acceptability of men seeking PCa supportive care [3]. Within the context of supportive care, prostate cancer support groups (PCSGs) have also emerged as important community-based resources for men and their partners $[4,5]$. As part of their engagement with their partner's health, some women attend PCSGs; yet the specificities and dynamics of how this plays out are poorly understood. The purpose of the current study was to explore and describe connections between heterosexual gender relations and $\mathrm{PCa}$ supportive care among couples who attend PCSGs.

\section{Prostate Cancer, Masculinities and Gender Relations}

Gender work in PCa has focused on describing how cancer and its treatments threaten masculine ideals including sexuality and self-reliance. Many men face the challenge of preserving their sense of masculinity while coping with the emasculating effects of treatment which include incontinence and sexual dysfunction [6-8]. In turn, these embodied changes are often internalized leaving men reluctant to discuss and/or seek help for PCa treatment side-effects $[9,10]$. While previous gender and PCa work has 
offered important insights, Wenger and Oliffe [11] highlighted the limitations of relying exclusively on men's narratives and masculinities frameworks.

Consensus prevails that within heterosexual relationships female partners are particularly important arbiters for many men who experience PCa [12-15]. Typically, such relations are embedded in traditional gender regimes whereby men perceive themselves as open to, requiring and deserving of spousal care, and women align to feminine ideals of nurturing, often directly managing or overseeing their male partner's health [5, 16-19]. For example, female partners can be the conduit for arranging their male partner's appointments with physicians [20] or the family's primary health care provider [21-23]. Broadly conceptualized as health-related social control [24] many women also actively encourage their male partners to seek medical care [14] amid taking notes and asking questions at their partner's health care consultations [18] and lobbying men to make dietary [19] and other lifestyle changes to bolster recovery from PCa [13]. In turn, having a partner is known to afford PCa specific benefits $[15,25]$ and, in general, married men are reported to be more likely to use preventative health care services [26].

Collectively, existing gender relations and PCa studies highlight two trends. First, women were committed to positively influencing the health practices of their male partners, a practice Bottorff et al [27] aligns with feminine ideals around nurturing and concern for others' well-being, and a compensatory measure for men's masculine estrangement from self-health. Second, in aligning to such traditional heterosexual gendered health relations many women use an array of tactics to more fully engage their partner with self-health [28]. The current study extends upon this work by exploring and 
describing connections between heterosexual gender relations and PCa supportive care among couples who attend PCSGs.

\section{Methods}

\section{Participants}

As part of a larger study we purposefully recruited 15 heterosexual couples between 2006-2009 from 9 PCSGs across British Columbia, Canada. All of the PCSGs were open to women attendees, though group formats differed in how the women attendees were engaged at the meetings. For example, while women contributed to the large group discussions some PCSGs also included breakout sessions where women attendees could meet separately. Participants had been attending PCSGs for 1 to 12 years (average 6 years). The men ranged in age from 57 to 81 years old $(M=72)$ and the female partners were between 60 to 84 years old ( $M=66)$. The majority of the participants were retired $(\mathrm{n}=27)$, and self-identified as Canadian $(\mathrm{n}=17)$ or of European ancestry $(n=13)$. Male participants had been diagnosed with PCa for 1 to 12 years $(M=6)$ and had received various treatments (Androgen deprivation therapy $(\mathrm{n}=10)$; radiation therapy $(\mathrm{n}=8)$; radical prostatectomy $(\mathrm{n}=3)$ and brachytherapy $(\mathrm{n}=3)$. The couples had been married for 10 to 50 years $(M=32)$.

\section{Data Collection}

After obtaining University of British Columbia ethics approval, 30 individual, semi-structured interviews lasting 60 to 90 minutes were conducted by trained qualitative research assistants. Interviewees received an honorarium of $\$ 20$ and were advised that the interview was an opportunity for us to better understand their experiences related to PCa 
as well as their relationship in the context of PCa supportive care and PCSGs. Whilst there are benefits and drawbacks to both individual and conjoint interview formats $[29$, 30], individual interviews were conducted because when couples are interviewed together one partner may dominate to produce a simplified 'official' account [31]. Interview questions which were the focus of this analysis included: How has PCa influenced your relationship and supportive care needs? And, how does attending a PCSG influence your relationship and supportive care? Probe and loop questions were used to solicit additional details [32]. Interviews were digitally recorded, transcribed verbatim, checked for accuracy and uploaded to qualitative data management software NVivo ${ }^{\mathrm{TM}}$. Each transcript was labelled with a unique identifier, and the couple interviews were linked.

\section{Data analysis}

Analysis was guided by interpretive descriptive traditions of qualitative research [33]. The analytic frames of interpretive description were used to engage the how and what of social realities, intentionally interpreting the data to inform practical health care applications [33]. Three authors led the analysis (JO, AW, LM) and read each couple's interviews to interpret the individual accounts (the man's account and his partner's account) and produce a “joint” or combined description of the couples' experiences. Couple dyad summaries were written (AW) to detail aspects of each couple's interactions around PCa supports and attendance at PCSGs. Summaries and corresponding individual interviews were compared and sorted into categories with attention to connections between heterosexual gender relations and PCa supportive care among the couples (JO, AW, LM). These processes were used to guide the development of a coding schedule and 
the interview data were subsequently coded in NVivo ${ }^{\mathrm{TM}}$. Preliminary findings were independently developed (JO, AW, LM) and discussed to inductively derive patterns, account for differences and decide on the thematic labels. The other authors (JB, DB, SLG) reviewed the coded data and each theme sharing their interpretations and providing feedback about the representativeness of the illustrative quotes and the organization of the findings. Through these processes, three patterns emerged. Overall, couples' accounts were interpreted, as carefully navigating traditional heterosexual gender relations whilst enabling men and their partners to gain the health supports they needed. The thematic findings describing these three patterns are outlined using illustrative quotes from the interviews. The names linked to the quotes are pseudonyms.

\section{Results}

Three themes were inductively derived; 1) "Not pushing too hard" - Balancing women's support with men's autonomy; 2) “Confreres" - Men supporting men at PCSGs; and, 3) "Women are better at reassuring" - Support from and for women. Though interconnected and not mutually exclusive the three themes are described separately below.

\section{1. "Not pushing too hard" - Balancing women's support with men's autonomy}

Participants referred to how they faced PCa together, as a 'team', and this frame of reference underscored PCa as a 'couple's disease'. Traditional heterosexual gender relations and roles shaped both men's and women's narratives wherein the women supported their male partners' health directly and indirectly by attending PCSGs. Explicitly expressed by couples were efforts to balance women's nurturing with men's 
autonomy in managing PCa. For example, $\mathrm{Al}$ described and affirmed the benefits of his wife's support in helping him process his PCa-related challenges:

She is very reassuring, but what the prostate cancer has done has helped us to talk about me and about this. My wife and I talk about it all the time. She says all the things I want to say, or hear, she is very supportive. (Al, 74-years-old)

This participant's wife Ann, in turn, described how she tactfully supported her husband by collecting and sharing PCa information, while also being careful to defer the decision making to him:

You get to a point where you get so much information, which is where we're at now. But I always ask [Al], "What do you think about it? What would you like to do?" (Ann, 65-years-old)

Evident here, and among many couples, was how women carefully supported men to help them make informed decisions about their PCa without appearing too directive. So while Ann dutifully collected PCa information, she was strategic in how she shared and leveraged what she found to influence and prompt, rather than to instruct or direct her husband. Many women appealed to their husbands to make informed decisions; however as Bev said of her 65-year-old husband Bob, it was important to "avoid pushing him too hard", elaborating:

I have to be really careful... he needs to think about things and come in at his own rate. (Bev, 64-years-old).

Within this context female partners were strategic in playing to masculine ideals through appealing to men's problem-solving abilities and desire for autonomy as a means to encourage them to invest in their health. The complexities for doing this were reflected by Deb, who carefully balanced her support role with the knowledge that her 71-year-old husband Dan, ultimately needed to assert that he had made his own treatment decision: 
I think we had decided or my husband, well we discussed his, the options available and he opted for brachytherapy and I think that was his decision. We studied the treatments... as I say we had made the decision pretty well on our own and of course I left it up to my husband, (Deb, 74-years-old)

Deb's narrative revealed stilted language alternating between "we" and "I", and "our" and "his" role: this signalled the skillful balance in having an opinion but not deciding for, or forcing her husband's decision. Using "we" talk she described their joint involvement and discussion amid providing assurances that Dan's independence and decisiveness, rather than her influence or lobbying, led he husband to make his treatment choice.

In contrast to the women's consistent references to "we", men routinely used the term "I" in asserting their lead, and in some cases downplaying their wife's involvement. Indeed, some discordant couple accounts emerged within this context. Seventy-eight year-old Ken explained, "I spent a lot of time out at the college library" while his wife Kim assured us of her support and involvement saying, "We went to the university library and got information”. Evident here was Ken's alignment to traditional masculine ideals related to independence, while Kim's womanly nurturing qualities, traditional feminine ideals, were highlighted in her account describing her support and their collaboration.

\section{2. "Confreres" - Men supporting men at PCSGs}

Many women recognized that because of the unique challenges of PCa and its treatments their husband would benefit by connecting with other men who were facing similar issues. PCSGs provided "ready-made" groups where men could meet other men 
and learn from each other's experiences. Bev, a 64-year-old woman avowed the importance of the male camaraderie, describing men at PCSGs as "a confrere, like in the same profession"; amid explaining that milieu had helped her husband connect with other men in a workman-like masculine context. PCSGs were seen to access positive masculinities by acknowledging the men as challenged by, but committed to solving a shared problem - PCa. Rather than being weak or vulnerable, investing in one's PCa and health was framed by participants as a wise, strength-based action.

The collective power of men was also at play wherein together the benefits afforded one another were understood as empowering, a contrast to traditional heterosexual gender relations in which women presumed the primary health advisor role, directing their men's health practices. Lynn, a 73-year-old woman explained:

Men's support from men is like a male bonding thing. You know, it's the group in the same boat sort of thing and it's a club...Support to men with a disease from women is more like being told what to do, isn't it? I mean support from their wives in that 'I care, you're still wonderful' you know, 'just go with it stay alive' that's good... as in love and compassion, that's great. But support from the men would be like sharing information, sharing stories, knowing that other people have dealt with this and are dealing with this. You know, 'life goes on.'

Evident here is Lynn's assertion that men's transactional support of one another, primarily sourced through testimonials and information sharing, a norm at PCSGs, drove actions, resilience and self-management toward recovery. Implicit also is that Lynn's support might quell as well as nourish differing masculine ideals.

While the benefits for men attending PSCGs were evident in Lynn's and many other's accounts, some participants suggested that men's conversations were nonetheless somewhat restricted by masculine norms - especially in terms of emotional sharing. 
Lynn's husband Lon, a 76-year-old man, described how male bonds tended to limit sharing about important health issues generally and at PCSGs:

Might be the macho thing. 'I'm a big, strong man', 'I don't get sick'. Or with their sexual ability. That's something men quite often joke about. But I don't think they very often get serious about it with other men. (Lon, 76-years-old)

Similarly, Oda, a 60-year-old woman, contrasted the limits of men connecting with one another compared to women:

Women tend to nurture, you know, whereas I would say male companionship, it's more like oh, you know, 'buck up' and more of a macho type thing. (Oda, 60years-old)

Nonetheless Oda echoed most of the other women who claimed their attendance at PCSGs signaled public support. She further explained the 'naturalness' of attending PCSG meetings with her partner, as what a "good wife" does:

That's what we do in all aspects of our life I think when we (women) go to the support group it's an outward show that we're backing them (men). (Oda, 60years-old)

These examples reveal that homo-social connections at PCSGs don't necessarily achieve the therapeutic benefits that they might, largely because men are governed by masculine norms that prohibit the linkages women often make with one another. Nonetheless, attending PCSGs demonstrated how women supported their husbands by physically being there, and by affirming the acceptability and value of men connecting with other men. 


\section{3. "Women are better at reassuring" - Support from and for women}

An important aspect of PCSGs was the provision of support for women; a benefit they might not find elsewhere, including from their husband. Gus encouraged his 72year-old wife Gia to connect with other women at the PCSG, recognizing that women linked to one another differently:

So women are better at reassuring them (other women). And they can talk about their own experience as a wife or partner. And how they dealt with things...in ways that probably they might not share with their husbands. (Gus, 74-years-old)

Evident here and among many men's narratives was recognition about their limits in fully supporting and reassuring their wives, amid assertions that other women might be better equipped to fill that void or augment what men could provide. Likewise, women acknowledged and welcomed the support they received at PCSGs. However, many women suggested connecting with other women bolstered their ability to provide support to their husbands. For example, Cas, a 72-year-old woman, asserted:

I'm on this journey with my husband and it's my life too and to be a support to him I can do a better job, you know, caregivers need support too. (Cas, 72-yearsold)

Evident here is the re-enforcement of feminine nurturing ideals wherein receiving support from other women is normed, as it easily interweaves into a larger enterprise of enabling women to more fully support their husbands. Many men confirmed this arrangement, including Hal, a 57-year-old who explained how his partner's support and skills for 'asking the right questions' about his health were bolstered through her interactions with other women at the PCSG: 
The other thing that's helpful is for her to see and hear from the other women about what their experience is which makes it, you know, causes her to ask me questions that she wouldn't have thought of otherwise. (Hal, 57-years-old)

Participants also agreed that having women attend PCSGs afforded an environment conducive to outward displays of support. Ned, a 66-year-old man suggested that while he did not himself share emotions at the group meetings, his wife was able to:

She adds to the group when she's talking to the other women and so forth. You know, she sort of blends in there and gives me, gives another side to me. And she sometimes shares with them how she feels about what I'm doing and how I've been and so forth where I might not say anything about it, you know. (Ned, 66years-old)

In this excerpt, allegiances to gender norms are evident both in who and how emotions were shared (or not) at PCSGs. However, rather than competing, the contrasting ways by which support was articulated and understood operationalized traditional heterosexual gender relations.

\section{Discussion}

The findings drawn from the current study reveal how traditional heterosexual gender relations can be relied upon as well as reformulated in terms of idealized roles about who does what in the context of PCa. In terms of reliance, confirmed are results from previous studies suggesting that women often look after the health of the men in their lives while supporting them through an array of PCa challenges [12-15, 25, 26, 34]. Additionally, the current study findings suggest that many woman play to men's masculine ideals round decision making and control as a means to engaging men with self-health. Similar to a study of men's depression [28], the women's support of men in 
the context of $\mathrm{PCa}$ emerged as strategic rather than entirely reflecting idealized femininities synonymous with nurturing others. Co-constructions of gender were also evident in women affirming the value of, and normalizing their husband's connections to other men at PCSGs. Positioning such linkages as strength-based rather than signaling weakness highlighted the power of the wives in norming masculine illness based 'confreres'. Indeed, the women's observations and references to the lack of emotional sharing amongst men at the PCSGs confirmed the masculine nature of the men's interactions. In turn, the men's self-proclaimed inability to fully meet the emotional needs of their partners amid suggestions that women draw great support from one another, relied on both masculine and feminine norms characterizing traditional heterosexual gender roles.

In sum, these findings confirm PCSGs as providing unique communities of practice [35] wherein relying on, and traversing gendered ideals makes available support to men and their partners. These findings add to a small but growing body of research that underscores the importance of accounting for gender relations in health and illness, rather than examining men's and women's health practices in isolation from one another [27, 28]. For example, strong empirical linkages between diet and PCa exist [36] but such insights should be thoughtfully considered in the context of couple interactions around food preparation and preferences [19]. In addition, the current study demonstrated a new avenue for exploring patient and family experiences of cancer, and the potential value of using a gender relations approach to guide the development of innovative programs to meet supportive care needs in a range of contexts. The findings also shed important light on how traditional heterosexual gender relations can garner supportive care, both in and 
outside spousal relationships at PCSGs. In this regard, while PCa couples' research and interventions have focused on couple's coping and distress [37, 38] as well as sexual rehabilitation [39], less attention has been paid to how gender relations influence men's decision making and help-seeking, and their uptake of services.

In terms of recommendations, more fully evaluating couples' interaction patterns across the PCa trajectory to inform pedagogical approaches for targeting supportive care services could be useful. In recognizing that PCSGs do not appeal to everyone, there may be an advantage to developing mechanisms for health care providers to evaluate which couples should be encouraged to attend a group meeting to connect with others regardless of their commitment to the group thereafter. For example, couples who are jointly engaged and orientated to other group based activities (e.g., bowls, bridge clubs) may be especially open to attending PCSGs. In addition, among couples where the man may not want to attend a PCSG but the woman partner does, health care providers might highlight the benefits afforded by women connecting with one another in lobbying men to consider attending a group to support their wife. Such strategies might ultimately yield benefits to men and women while extending the reach of PCSGs.

The findings from this study are not generalizable, and the participant couples might be reasonably argued as unique and somewhat atypical in attending PCSGs for an average of six years. That said, the important insights regarding the joint engagement of this support process for that length of time may shed some light on how couples approach the PCa experience in other contexts. In terms of future research, there is likely to be benefit to further exploring the role of gender relations to compare and distil changes to 
supportive care needs across the PCa trajectory as a means to developing tailored PCa supports for men and their partners.

\section{Conclusion}

Gender relations analyses are integral to advancing understandings about the supportive care needs of men who experience PCa and their partners. While the sustainability of PCSGs can be challenged [40], a focus on recruiting couples highlighting the many individual and joint benefits may be key to increasing PCSG membership and the availability of much needed PCa supports for couples. Understanding about how couples approach men's PCa supportive care may also be used to inform the development of other types of gender-sensitive psychosocial supports.

\section{Acknowledgements}

This study was made possible by the Canadian Institutes of Health Research (CIHR) (Institute of Gender and Health (IGH)) (\#11R91563). Thanks to Robin Barnett for her input to preliminary data analyses and Lisa Wenger for writing to an early draft of this article. L. Mróz would also like to thank CIHR for funding (Post-doctoral Fellowship, IGH) and the Men's Health Initiative BC for their support.

\section{CoI statement}

The authors have no conflict of interest to declare. This research was funded by a grant from the Canadian Institutes for Health Research (CIHR - Institute of Gender and Health grant \#11R91563 awarded to John Oliffe. Lawrence Mróz received Post-doctoral Fellowship salary funding from CIHR (IGH). The authors do not have other financial relationships with CIHR. The authors have full control of all primary data and agree to allow the journal to review their data if requested. 


\section{References}

1. CCS (2014) Canadian Cancer Society's Advisory Committee on Cancer Statistics. Canadian Cancer Statistics 2014. Toronto, ON: Canadian Cancer Society.

2. Steginga SK, Occhipinti S, Dunn J, et al. (2001) The supportive care needs of men with prostate cancer. Psychooncology 10:66-75. doi: 10.1002/10991611(200101/02)10:1<66::AID-PON493>3.0.CO;2-Z

3. Soloway CT, Soloway MS, Kim SS, Kava BR (2005) Sexual, psychological and dyadic qualities of the prostate cancer "couple". BJU Int 95:780-785. doi: 10.1111/j.1464-410X.2005.05400.x

4. Arrington MI, Grant CH, Vanderford ML (2005) Man to Man and Side by Side, They Cope with Prostate Cancer. J Psychosoc Oncol 23:81-102. doi:

10.1300/J077v23n04_05

5. Bottorff JL, Oliffe JL, Halpin M, et al. (2008) Women and prostate cancer support groups: The gender connect? Soc Sci Med 66:1217-1227. doi: 10.1016/j.socscimed.2007.11.018

6. Fergus KD, Gray RE, Fitch MI (2002) Sexual Dysfunction and the Preservation of Manhood: Experiences of Men with Prostate Cancer. J Health Psychol 7:303-316.

7. Oliffe JL (2005) Constructions of masculinity following prostatectomy-induced impotence. Soc Sci Med 60:2249-2259. doi: 10.1016/j.socscimed.2004.10.016

8. Oliffe JL (2006) Embodied masculinity and androgen deprivation therapy. Sociol Health Illn 28:410-432.

9. Chapple A, Ziebland S (2002) Prostate cancer: Embodied experience and perceptions of masculinity. Sociol Health Illn 24:820-841.

10. Oliffe JL, Thorne S (2007) Men, masculinities, and prostate cancer: Australian and Canadian patient perspectives of communication with male physicians. Qual Health Res 17:149-61. doi: 10.1177/1049732306297695

11. Wenger LM, Oliffe JL (2012) Moving Beyond the Prostate: Benefits in Broadening the Scope of Research on Men and Cancer. Am J Mens Health. doi: $10.1177 / 1557988312463420$ 
12. Bowie J V, Sydnor KD, Granot M, Pargament KI (2005) Spirituality and Coping Among Survivors of Prostate Cancer. J Psychosoc Oncol 22:41-56. doi: 10.1300/J077v22n02_03

13. Fergus KD, Gray RE, Fitch MI, et al. (2002) Active Consideration: Conceptualizing Patient-Provided Support for Spouse Caregivers in the Context of Prostate Cancer. Qual Health Res 12:492-514. doi: 10.1177/104973202129120034

14. Arrington MI (2005) "She's Right Behind Me All the Way": An Analysis of Prostate Cancer Narratives and Changes in Family Relationships. J Fam Commun 5:141162. doi: 10.1207/s15327698jfc0502_5

15. Forbat L, Place M, Hubbard G, et al. (2014) The role of interpersonal relationships in men's attendance in primary care: qualitative findings in a cohort of men with prostate cancer. Support Care Cancer 22:409-15. doi: 10.1007/s00520-013-1989-y

16. Boehmer U, Clark JA (2001) Married couples' perspectives on prostate cancer diagnosis and treatment decision-making. Psycho-Oncology 155:147-155. doi: 10.1002/pon.504

17. Gray RE, Fitch M, Davis C, Phillips C (1996) Breast cancer and prostate cancer selfhelp groups: reflections on differences. Psychooncology 5:137-142.

18. Heyman EN, Rosner TT (1996) Prostate cancer: an intimate view from patients and wives. Urol Nurs 16:37-44.

19. Mróz LW, Chapman GE, Oliffe JL, Bottorff JL (2011) Gender relations, prostate cancer and diet: re-inscribing hetero-normative food practices. Soc Sci Med 72:1499-506. doi: 10.1016/j.socscimed.2011.03.012

20. Boehmer U, Babayan RK (2005) A pilot study to determine support during the pretreatment phase of early prostate cancer. Psychooncology 14:442-449. doi: $10.1002 /$ pon.859

21. Feltwell AK, Rees CE (2004) The information-seeking behaviours of partners of men with prostate cancer: a qualitative pilot study. Patient Educ Couns 54:179-85. doi: 10.1016/S0738-3991(03)00212-X

22. O'Rourke ME, Germino BB (1998) Prostate cancer treatment decisions: a focus group exploration. Oncol Nurs Forum 25:97-104.

23. Srirangam SJ, Pearson E, Grose C, et al. (2003) Partner's influence on patient preference for treatment in early prostate cancer. BJU Int 92:365-369. doi: 10.1046/j.1464-410X.2003.04355.x 
24. Helgeson VS, Novak S a., Lepore SJ, Eton DT (2004) Spouse Social Control Efforts: Relations to Health Behavior and Well-Being among Men with Prostate Cancer. J Soc Pers Relat 21:53-68. doi: 10.1177/0265407504039840

25. Abdollah F, Sun M, Thuret R, et al. (2011) The effect of marital status on stage and survival of prostate cancer patients treated with radical prostatectomy: a populationbased study. Cancer Causes Control 22:1085-95. doi: 10.1007/s10552-011-9784-x

26. Blumberg SJ, Ph D, Vahratian A, Blumberg JH (2014) Marriage, Cohabitation, and Men's Use of Preventive Health Care Services. NCHS Data Brief 154: Hyattsville, MD: National Center for Health Statistics June 2014.

27. Bottorff JL, Haines-Saah R, Oliffe JL, Sarbit G (2012) Gender influences in tobacco use and cessation interventions. Nurs Clin North Am 47:55-70. doi: 10.1016/j.cnur.2011.10.010

28. Oliffe JL, Kelly MT, Bottorff JL, et al. (2011) "He's more typically female because he's not afraid to cry": Connecting heterosexual gender relations and men's depression. Soc Sci Med 73:775-782. doi: 10.1016/j.socscimed.2011.06.034

29. Morris SM (2001) Joint and Individual Interviewing in the Context of Cancer. Qual Health Res 11:553-567. doi: 10.1177/104973201129119208

30. O'Rourke ME, Germino BB, O'Rourke ME (2000) From Two Perspectives to One Choice: Blending Couple and Individual Views of Prostate Cancer Treatment Selection. J Fam Nurs 6:231-251. doi: 10.1177/107484070000600303

31. Hertz R (1995) Separate But Simultaneous Interviewing of Husbands and Wives: Making Sense of Their Stories. Qual Inq 1:429-451. doi: $10.1177 / 107780049500100404$

32. Oliffe JL, Mróz LW (2005) Men interviewing men about health and illness: Ten lessons learned. J Men's Heal Gend 2:257-260.

33. Thorne S (2008) Interpretive Description. Left Coast Press, Walnut Creek, CA

34. Gray RE, Fitch M, Phillips C, et al. (2000) Managing the Impact of Illness: The Experiences of Men with Prostate Cancer and their Spouses. J Health Psychol 5:531-48. doi: 10.1177/135910530000500410

35. Creighton G, Oliffe JL (2010) Theorising masculinities and men's health: A brief history with a view to practice. Heal Sociol Rev 19:409-418. doi:

10.5172/hesr.2010.19.4.409 
36. Mróz LW, Chapman GE, Oliffe JL, Bottorff JL (2010) Prostate cancer, masculinity and food. Rationales for perceived diet change. Appetite 55:398-406. doi:

10.1016/j.appet.2010.07.009

37. Chambers S, Schover L, Nielsen L, et al. (2013) Couple distress after localised prostate cancer. Support Care Cancer 21:2967-2976. doi: 10.1007/s00520-0131868-6

38. Winters-Stone K, Lyons K, Bennett J, Beer T (2014) Patterns and predictors of symptom incongruence in older couples coping with prostate cancer. Support Care Cancer 22:1341-1348. doi: 10.1007/s00520-013-2092-0

39. Hampton AD, Walker L, Beck A, Robinson J (2013) A brief couples' workshop for improving sexual experiences after prostate cancer treatment: a feasibility study. Support Care Cancer 21:3403-3409. doi: 10.1007/s00520-013-1922-4

40. Oliffe JL, Halpin M, Bottorff JL, et al. (2008) How Prostate Cancer Support Groups Do and Do Not Survive: British Columbian Perspectives. Am J Mens Health 2:143155. doi: $10.1177 / 1557988307304147$ 